\title{
Combined use of adenoviral vector Ad5/F35-mediated APE1 siRNA enhances the therapeutic efficacy of adenoviral-mediated p53 gene transfer in hepatoma cells in vitro and in vivo
}

\author{
YANPING CUN $^{1 *}$, QINHONG ZHANG ${ }^{1 *}$, CHENGJIE XIONG $^{2}$, \\ MENGXIA LI $^{1}$, NAN DAI ${ }^{1}$, SHIHENG ZHANG $^{1}$ and DONG WANG ${ }^{1}$ \\ ${ }^{1}$ Cancer Center, Daping Hospital and Research Institute of Surgery, Third Military Medical University, Chongqing 400042; \\ ${ }^{2}$ Department of Orthopedics, Xinqiao Hospital, Third Military Medical University, Chongqing 400037, P.R. China
}

Received January 17, 2013; Accepted February 14, 2013

DOI: $10.3892 / o r .2013 .2384$

\begin{abstract}
Gene therapy has emerged as a novel therapeutic approach for the treatment of cancer. In order to establish a more effective therapeutic strategy against unresectable hepatocellular carcinoma (HCC), we evaluated, in the present study, the effects of combined treatment with adenoviral vector Ad5/F35-mediated APE1 siRNA (Ad5/F35-siAPE1) and adenoviral-mediated p53 gene transfer (Ad-p53) in hepatoma cells in vitro and in vivo. Infection of SMMC-7721 cells with Ad5/F35-siAPE1 resulted in a time- and dose-dependent decrease of APE1 protein, while Ad-p53 treatment led to a time- and dose-dependent increase of p53 protein expression. Ad5/F35-siAPE1 significantly enhanced the cytotoxic effect of SMMC-7721 cells to Ad-p53 in cell survival assays, associated with increased cell apoptosis. Moreover, administration of Ad5/F35-siAPE1 and Ad-p53 into nude mice resulted in tumor growth inhibition and apoptosis induction in SMMC-7721 xenografts compared to administration of either agent alone. These results suggest that combination of Ad5/F35-siAPE1 and Ad-p53 could be a promising gene therapeutic approach against human HCC.
\end{abstract}

\section{Introduction}

Hepatocellular carcinoma (HCC) is one of the most common malignant diseases with 600,000 new cases reported each year worldwide, and is the third leading cause of cancer-related mortality (1). Although aggressive surgery offers significant rates of cure, only $15 \%$ of patients are eligible for optimal

Correspondence to: Professor Dong Wang, Cancer Center, Daping Hospital and Research Institute of Surgery, Third Military Medical University, Chongqing 400042, P.R. China

E-mail: dongwang64@hotmail.com

${ }^{*}$ Contributed equally

Key words: hepatocellular carcinoma, human apurinic/apyrimidinic endonuclease, p53, adenoviral vector, gene therapy resection at diagnosis. The efficacy of chemotherapy and radiotherapy for HCC remain disappointing. Gene therapy may be a promising approach for the treatment of HCC.

The tumor suppressor gene p53 plays a key role in cell cycle control, apoptosis and inhibition of tumor cell proliferation. Several human tumors carry mutations in the p53 and mutation or deletion of p53 is associated with poor prognosis and resistance to chemotherapy and radiotherapy $(2,3)$. In HCC, absent p53 status is correlated with carcinogenesis, and p53 is frequently mutated in $\mathrm{HCC}$ and its presence indicates a poorer prognosis (4,5). A number of groups have reported the clinical responses to adenovirus p53 (Ad-p53) as a single agent or combined with radiotherapy or chemotherapy, including head and neck squamous cell carcinoma, breast cancer, non-small cell lung cancer, glioma, bladder and esophageal cancer (6-10). Recent studies revealed that combined gene therapy is more effective in treating the murine model of HCC than therapy with one gene alone $(11,12)$.

Human apurinic/apyrimidinic endonuclease (APE1) is a dual-function protein, which has both DNA repair activity and redox regulatory activity (13). As a redox factor, APE1 maintains a number of transcriptional factors including p53 in their reduced and active state, thereby regulating their DNA-binding activity $(14,15)$. Several studies demonstrated that APE1 was overexpressed in several human tumors and elevated APE1 level was associated with poor clinical outcome (16-21). In a previous study, we constructed chimeric adenoviral vector Ad5/ F35 carrying human APE1 siRNA (Ad5/F35-siAPE1), which inhibited APE1 expression and enhanced the sensitivity to radiotherapy in colorectal cancer (22). Moreover, we found that Ad5/F35-siAPE1 enhanced sensitivity to cisplatin, including ovarian cancer (23) and non-small cell lung cancer (24). Since silencing of APE1 enhanced the sensitivity to radiotherapy and chemotherapy, inhibition of APE1 protein by Ad5/F35-siAPE1 may be a promising approach against cancer.

In the present study, we examined the therapeutic effectiveness of combined Ad5/F35-siAPE1 and Ad-p53 in vitro and in a murine model of HCC. Our data demonstrate that combined gene therapy with Ad5/F35-siAPE1 and Ad-p53 was more effective than therapy with either agent alone in HCC cells in vitro and in vivo. 


\section{Materials and methods}

Materials. Adenovirus vector Ad5/F35-siAPE1 carrying human APE1 siRNA sequence was constructed and purified as previously described (22). Ad-p53 was obtained from Shenzhen SiBiono GeneTech Co., Ltd. (Shenzhen, China). The control adenovirus, Ad-EGFP and Ad5/F35-EGFP, was purchased from Vector Gene Technology Co., Ltd. (Beijing, China). The monoclonal antibody against hAPE1 was from Novus Biological (Littleton, CO, USA). The antibodies directed against p53 (DO-1) and $\beta$-actin were purchased from Santa Cruz Biotechnology (Santa Cruz, CA, USA). The human hepatoma cell line SMMC-7721 (carrying wildtype p53) was obtained from the Cell Institute of Shanghai (Academia Sinica, Shanghai, China). Cells were maintained at $37^{\circ} \mathrm{C}$ in a humidified incubator under $5 \% \mathrm{CO}_{2}$ and grown in Dulbecco's modified Eagle's medium (DMEM) supplemented with $10 \%$ fetal bovine serum, $50 \mathrm{mg} / \mathrm{ml}$ penicillin/ streptomycin. Specific pathogen-free female athymic nude mice, 4-6 weeks old, were purchased from Shanghai SLAC Laboratory Animal Co., Ltd. (Shanghai, China). All experiments were carried out in accordance with the China Animal Welfare Legislation and were approved by the Third Military Medical University Committee on Ethics in the Care and Use of Laboratory Animals.

Infection with adenoviruses and flow cytometry. SMMC-7721 cells were infected with Ad5-EGFP or Ad5/F35-EGFP with increasing multiplicities of infection (MOI) for $2 \mathrm{~h}$ and were then washed to remove the adenoviruses. They were cultured for another $48 \mathrm{~h}$ and then analyzed for their EGFP intensity using a FACScan (Becton-Dickinson, Mountain View, CA, USA) or directly observed with a fluorescence microscope (1200 ECM; Nikon, Düsseldorf, Germany).

Western blot analysis. Ten million cells were supplemented with $100 \mu \mathrm{l}$ cell lysis solution precooled to $0^{\circ} \mathrm{C}$ left on ice for $30 \mathrm{~min}$, centrifuged at $12,000 \mathrm{rpm}$ and placed at room temperature for $10 \mathrm{~min}$. Supernatants were supplemented with $2 \mathrm{X}$ sodium dodecyl sulfate (SDS) gel loading buffer and denatured at $100^{\circ} \mathrm{C}$ for $5 \mathrm{~min}$. Then, $20 \mu \mathrm{g}$ of protein from nuclear, cytosolic, or mitochondrial fractions was applied to $10 \%$ SDS-polyacrylamide gels and electrophoresed to resolve proteins. The proteins were then transferred to polyvinylidene difluoride (PVDF) membranes and blocked in Tris-buffered saline and Tween-20 (TBST) [50 mM Tris- $\mathrm{HCl}, \mathrm{pH} 7.5$, $150 \mathrm{mM} \mathrm{NaCl}$ and $0.1 \%(\mathrm{v} / \mathrm{v})$ Tween-20] containing $5 \%(\mathrm{w} / \mathrm{v})$ defatted milk and incubated with the specific primary antibody. The membranes were then washed three times in TBST and incubated with a horseradish peroxidase-conjugated secondary antibody $(1: 2,000)$ (Pierce) for $1 \mathrm{~h}$ at $37^{\circ} \mathrm{C}$. The membranes were then washed three times with TBST and the blots were reacted with chemiluminescence reagents and revealed with BioMax Light film (Kodak, Rochester, NY, USA). Band intensities were analyzed using the Gel Doc 2000 apparatus and software (Quantity One; Bio-Rad Laboratories, Hercules, CA, USA). Suppliers of incubation conditions for antibodies used for western blot analysis were as follows: anti-APE1 monoclonal (Novus), $1 \mathrm{~h}$ at $37^{\circ} \mathrm{C}$, dilution 1:5,000; anti-p53 monoclonal antibody (DO-1), overnight at $4^{\circ} \mathrm{C}$, dilution 1:500; anti- $\beta$-actin monoclonal (Santa Cruz Biotechnology), $1 \mathrm{~h}$ at $37^{\circ} \mathrm{C}$, dilution $1: 2,000$.

MTT assay. Cells $\left(1 \times 10^{5}\right.$ cells $\left./ \mathrm{ml}\right)$ were immediately inoculated into 96 -well plates $(200 \mu \mathrm{l} /$ well) in triplicate post-irradiation. After $72 \mathrm{~h}, 15 \mu \mathrm{l}$ MTT $(5 \mathrm{mg} / \mathrm{ml})$ was added to each well and incubated for $4 \mathrm{~h}$ in a humidified atmosphere $\left(37^{\circ} \mathrm{C}, 5 \% \mathrm{CO}_{2}\right)$. The culture medium was removed and $200 \mu \mathrm{l}$ of DMSO was added into each well. The plates were shaken on a swing bed for $10 \mathrm{~min}$ and the OD value at $492 \mathrm{~nm}$ was determined using a microplate reader.

In vivo experiments. SMMC-7721 cells $\left(5 \times 10^{6}\right)$ in $100 \mu 1$ phosphate-buffered saline (PBS) were injected subcutaneously into the right flank of nude mice. When the tumors grew to $\sim 100 \mathrm{~mm}^{3}$ on Day 12 after cell injection, 16 tumor-bearing mice were randomized into the following four treatment groups ( $n=4$ animals per group): i) Ad5/ F35-EGFP+Ad-EGFP; ii) Ad5/F35-siAPE1+Ad-EGFP; iii) Ad5/F35-EGFP+Ad-p53; iv) Ad5/F35-siAPE1+Ad-p53. Tumor-bearing mice were injected with the aforementioned agents directly into the tumors every 3 days. On Day 18, all nude mice were sacrificed, and each tumor was isolated and measured. The maximum diameters (Dmax) and minimum diameters (Dmin) of xenografts were measured before each treatment and after mice were sacrificed, and tumor size was calculated according to the following formula: tumor size $\left(\mathrm{mm}^{3}\right)=\left(\operatorname{Dmax} \times \operatorname{Dmin}^{2}\right) / 2$.

Immunohistochemical analysis of tumors for APE1 and $p 53$. The expressions of APE1 and p53 protein were analyzed using immunohistochemistry. Sections from paraffin-embedded tumors were incubated overnight with mouse anti-human APE1 monoclonal antibody (Novus) at a 1:2,000 dilution or anti-p53 antibody (DO-1) (Santa Cruz Biotechnology) at a 1:500 dilution, and then incubated with goat anti-mouse secondary antibody (Pierce, Rockford, IL, USA). Antigenantibody complexes were visualized by incubation with 3,3'-diaminobenzidine (DAB) substrate and counterstained with diluted Harris hematoxylin.

TUNEL assay for apoptosis. In vitro, coverslips covered with SMMC-7721 cells were rinsed in PBS and fixed with 4\% paraform, and then measured by terminal dUTP nick end labeling (TUNEL) staining using the ApopTag kit (Intergen, Purchase, NY, USA). The formalin-fixed and paraffin-embedded $5 \mu \mathrm{m}$ sections of all tumor samples were also analyzed for apoptosis by TUNEL assay. The extent of apoptosis was evaluated by counting the positive brown-stained cells as well as the total number of cells at 10 arbitrarily selected x100 microscope fields in a blinded manner.

Statistical analysis. All quantitative data were obtained from at least three independent experiments and expressed as the means $\pm \mathrm{SD}$. The statistical significance of differences was determined by the Student's two tailed t-test in two groups and by one-way analysis of the variance (ANOVA) using computer SPSS software SPSS 10.0 (SPSS Inc., Chicago, IL, USA). $\mathrm{P}<0.05$ was considered to indicate a statistically significant difference. 

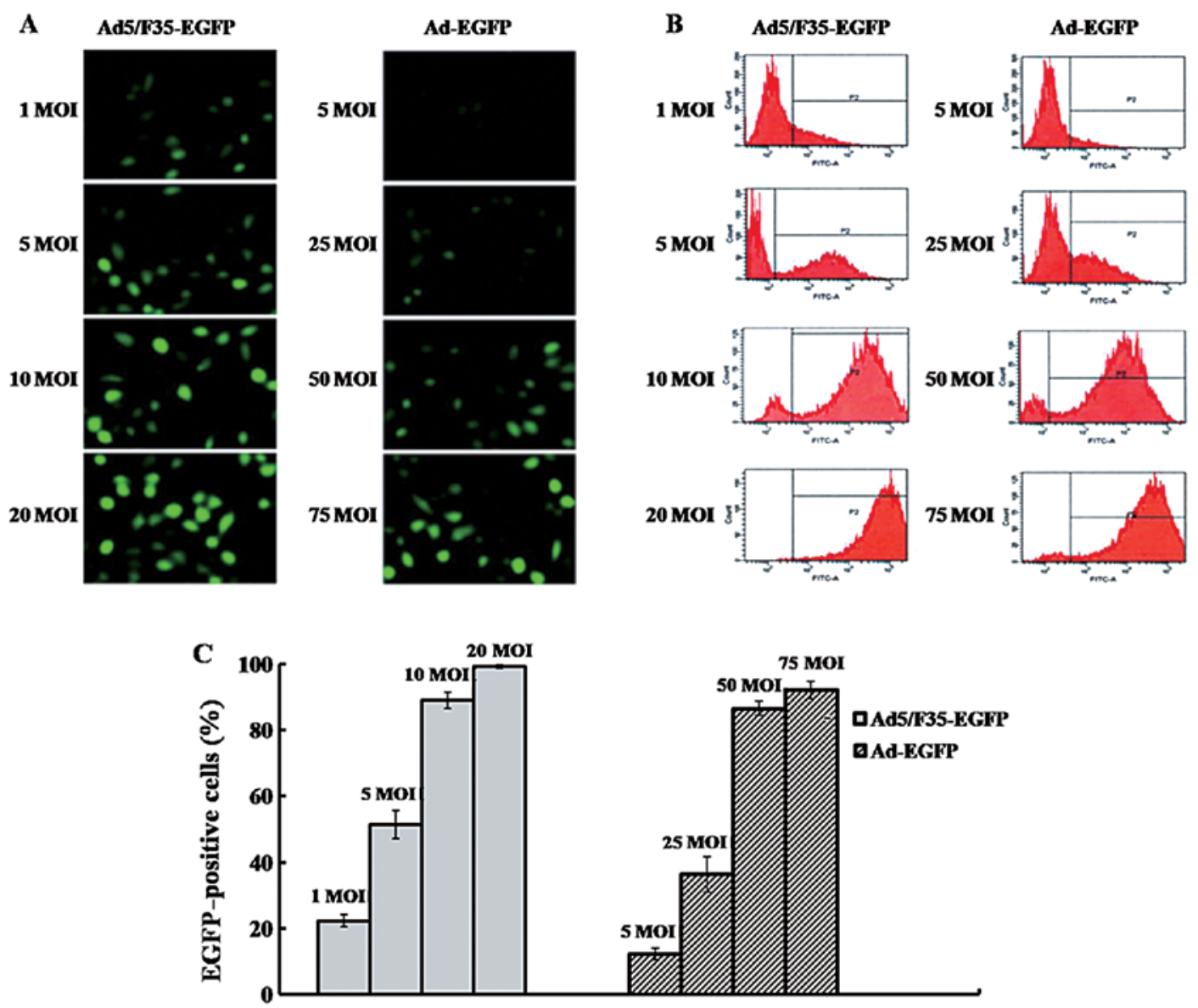

Figure 1. The adenovirus vector presents high infectivity in SMMC-7721 cells. SMMC-7721 cells were infected with Ad5-EGFP or Ad5/F35-EGFP with increasing MOI. (A) Direct detection of EGFP fluorescence by fluorescence microscopy to assay adenovirus vector infectivity. (B) Representative expression profiles and (C) percentage of adenovirus infected EGFP-positive cells examined with flow cytometry. Each data point represents the means \pm standards (SD) of at least three independent experiments.

\section{Results}

Infectivity of adenovirus vectors Ad5/F35 and Ad5 to human hepatoma cells. We examined the transduction efficiency of Ad5/F35-EGFP and Ad5-EGFP to SMMC-7721 cells. As the same promoter was used to transcribe the EGFP gene in all vectors, the EGFP-positive population was primarily determined by the adenovirus infectivity. We thereby regarded the percentage of positive EGFP cells as putative infectivity of adenoviruses in the present study. The infectivity of Ad5/F35-EGFP and Ad5-EGFP increased in a dose-dependent manner (Fig. 1A and B). The infectivity with $10 \mathrm{MOI}$ Ad5/F35-EGFP following transduction was $89 \%$, and increased to $99.1 \%$ with 20 MOI Ad5/F35-EGFP. Moreover, the infectivity of $50 \mathrm{MOI}$ Ad5-EGFP was $86.5 \%$, and reached 92.1\% with 75 MOI Ad5-EGFP (Fig. 1C).

Cell survival following adenovirus infection in SMMC-7721 cells. To investigate the cell survival of SMMC-7721 cells following adenovirus infectivity, MTT assays were performed. As shown in Fig. 2A, Ad5/F35-siAPE1 inhibited cell growth in a dose-dependent manner, compared with the Ad5/F35-EGFP group. Although the cell survival decreased to $61.06 \%$ after 40 MOI Ad5/F35-siAPE1, there was no significant difference compared with that after 20 MOI Ad5/F35-siAPE1, which had an inhibition rate of 63\%. Since 99.1\% SMMC-7721 cells showed EGFP-positive cells (Fig. 1C) and the cell survival reached in $98.91 \%$ after 20 MOI Ad5/F35-EGFP infection (Fig. 2A), the dose of $20 \mathrm{MOI}$ was used in following assays.

Subsequently, we showed that the cell proliferation of SMMC-7721 cells was inhibited by Ad-p53 in a dosedependent manner, and 100 MOI Ad-p53 almost completely suppressed the cell growth. At lower doses, Ad-EGFP caused slight damage to cells, but the cell survival declined to $91.31 \%$ after a higher 100 MOI Ad-EGFP transfection (Fig. 2B). Due to the high adenovirus infectivity of SMMC-7721 cells at 50 MOI Ad-EGFP and significant inhibition caused by $50 \mathrm{MOI}$ Ad-p53, the dose of 50 MOI was used in following assays.

Time course and dose-dependent expression of APE1 and p53 proteins following adenovirus transfection. We examined the expression of APE1 protein in SMMC-7721 cells following Ad5/F35-siAPE1 treatment. Fig. 3A shows that Ad5/F35-siAPE1 inhibited APE1 protein expression levels in a dose-dependent manner, and the inhibition rate of APE1 reached $>90 \%$ with 20 MOI of Ad5/F35-siAPE1. Then, we analyzed the expression of p53 protein following Ad-p53 treatment in SMMC-7721 cells, and found that p53 protein increased in a dose-dependent manner following infection with Ad-p53 (Fig. 3B). 

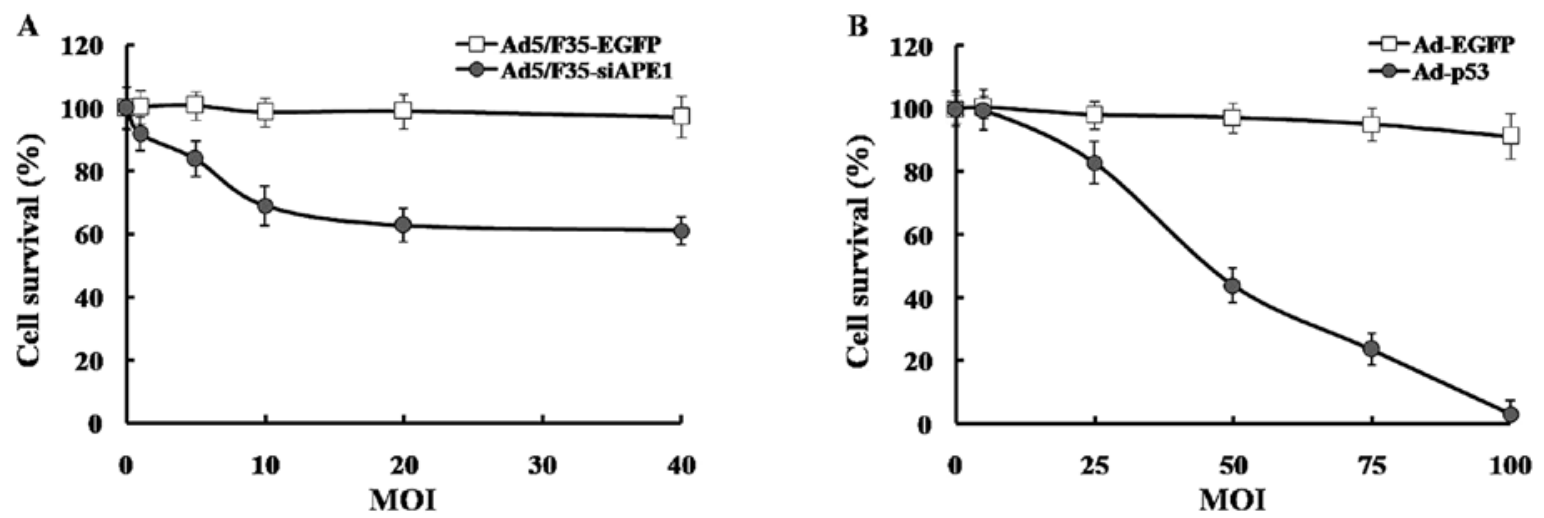

Figure 2. Cell survival following treatment with Ad5/F35-siAPE1 or Ad-p53. SMMC-7721 cells were treated with (A) Ad5/F35-siAPE1 or (B) Ad-p53; 48 h after infection, cells were collected and evaluated by MTT assay. The data represent the mean values of at least three independent experiments \pm SD.
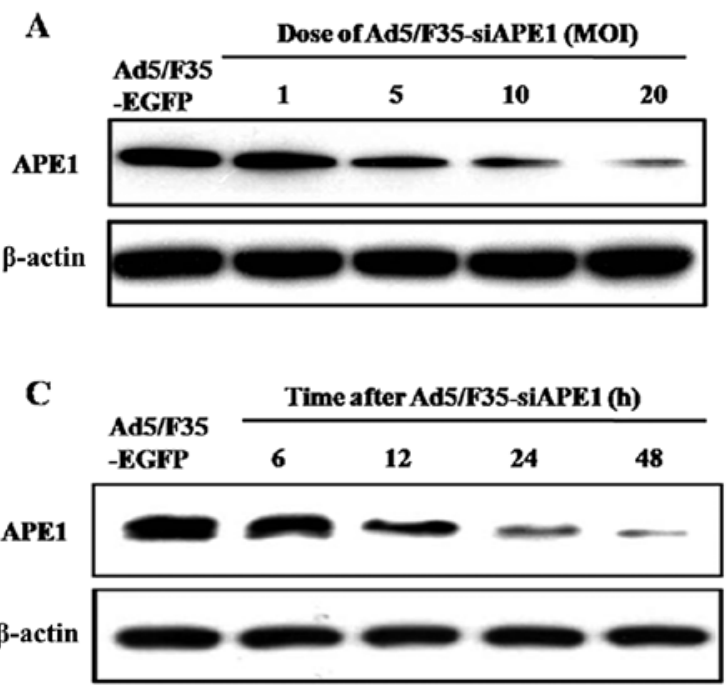
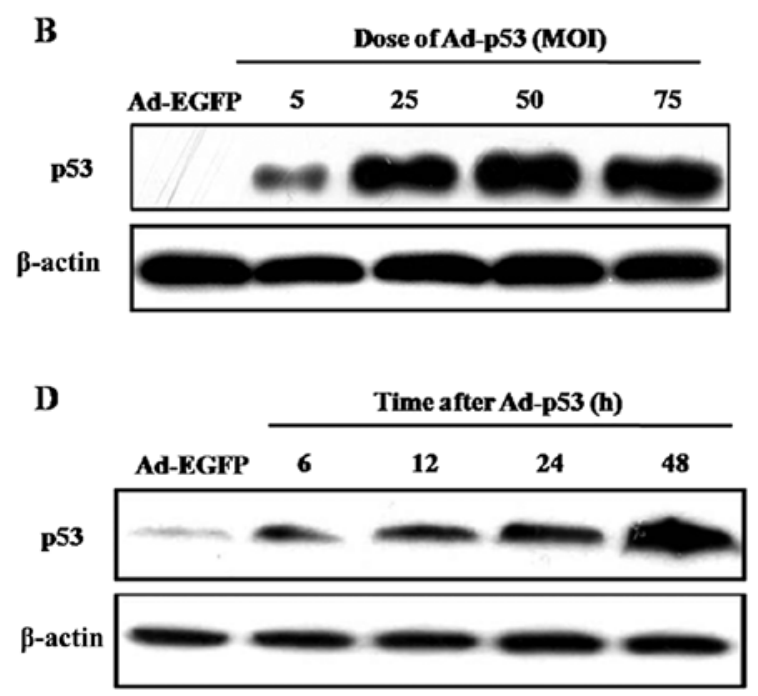

Figure 3. Time course and dose-dependent expression of APE1 and p53 proteins following Ad5/F35-siAPE1 or Ad-p53 treatment. SMMC-7721 cells were treated with increasing MOI of Ad5/F35-siAPE1 or Ad-p53, and then western blot analysis was performed at $48 \mathrm{~h}$ post-infection with (A) APE1 or (B) p53 antibodies, and reprobed with $\beta$-actin antibody as a loading control. The protein expressions of APE1 and p53 were analyzed at $6,12,24$ and $48 \mathrm{~h}$ after (C) 20 MOI Ad5/F35-siAPE1 or (D) 50 MOI Ad-p53 transfected to SMMC-7721 cells.

We further investigated the time-dependent effect of APE1 following Ad5/F35-siAPE1 transfection, and found that the APE1 expression level was markedly decreased in a timedependent manner in $20 \mathrm{MOI}$ Ad5/F35-siAPE1-transfected SMMC-7721 cells, and the suppression rate of APE1 reached $\sim 90 \%$ at $48 \mathrm{~h}$ after infection (Fig. 3C). We also observed that there was a time-dependent increase of p53 protein in $50 \mathrm{MOI}$ Ad-p53-transfected SMMC-7721 cells (Fig. 3D).

Combined Ad5/F35-siAPE1 and Ad-p53 potentiates cell growth inhibition and apoptosis induction in vitro. To examine the suppression of Ad5/F35-siAPE1 in combination with Ad-p53, the cellular proliferation capacity was detected by MTT assay in the SMMC-7721 cell line. As shown in Fig. 4A, a significant cell proliferation inhibition was observed in the Ad5/F35-EGFP+Ad-p53, Ad5/F35-si APE1+Ad-EGFP or Ad5/F35-siAPE1+Ad-p53 group, compared with the Ad5/F35-EGFP+Ad-EGFP control group. The combined Ad5/F35-siAPE1 and Ad-p53 group caused a significant inhibition of cell growth compared with the Ad5/F35-siAPE1 or the Ad-p53 treatment group alone. However, no statistical differences were found between the Ad5/F35-EGFP+Ad-p53 and Ad5/F35-siAPE1+Ad-EGFP groups.

In another series of experiments, cells were collected at $48 \mathrm{~h}$ following adenovirus treatment, and apoptotic cells were measured by TUNEL assay. As shown in Fig. 4B and C, the apoptotic rates of the Ad5/F35-EGFP+Ad-EGFP control group, Ad5/F35-siAPE1+Ad-EGFP, Ad5/F35-EGFP+Ad-p53 and Ad5/F35-siAPE1+Ad-p53 were 2.10 $\pm 0.41,5.73 \pm 1.02$, $6.57 \pm 1.19$ and $17.82 \pm 3.02 \%$, respectively. Ad5/F35-siAPE1 or Ad-p53 alone induced a slight increase in apoptotic cells compared with the Ad5/F35-EGFP+Ad-EGFP control group, while Ad5/F35-siAPE1 combined with Ad-p53 significantly increased cell apoptosis induction. Collectively, our data demonstrate that combined Ad5/F35-siAPE1 and Ad-p53 enhance cell growth inhibition and apoptosis induction in the human SMMC-7721 cell line.

APE1 and p53 protein expression in vivo. To investigate the expression levels of APE1 and p53 protein with or without 
A

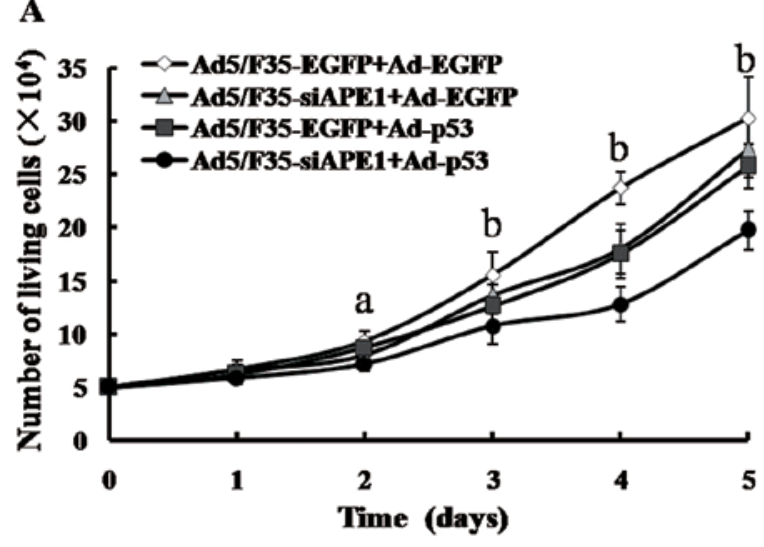

C

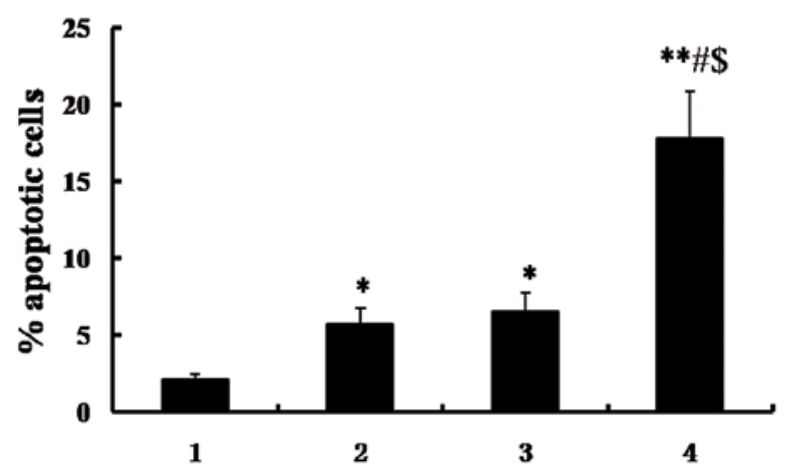

B
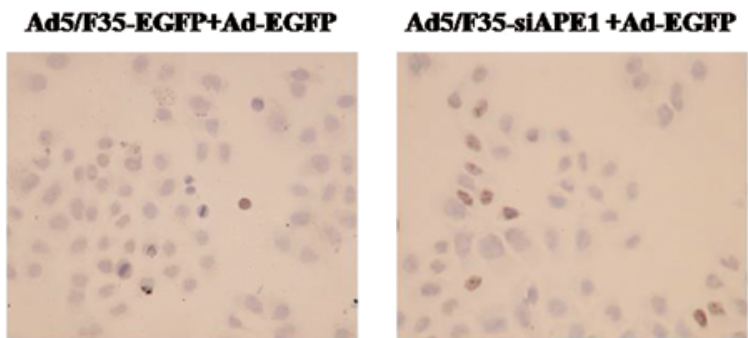

Ad5/F35-EGFP+Ad-p53

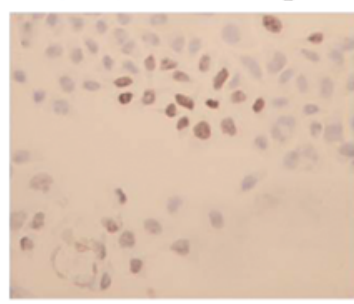

Ad5/F35-siAPE1 +Ad-p53

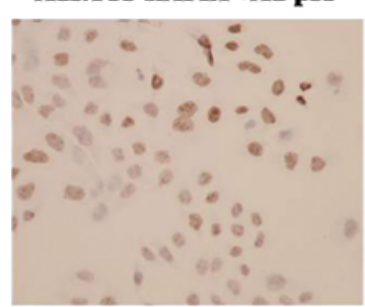

Figure 4. Combined Ad5/F35-siAPE1 and Ad-p53 inhibit cell growth and enhance apoptosis induction in vitro. (A) SMMC-7721 cells were treated with Ad5/F35-siAPE1 and/or Ad-p53; MTT assays were used to determine the cell survival. (a) The cell survival of the Ad5/F35-siAPE1+Ad-p53 group differed significantly from the Ad5/F35-EGFP+Ad-EGFP control group, but there were no statistical differences among other groups. (b) The tumor volume differed significantly among all treated groups, except between the Ad5/F35-siAPE1+Ad-EGFP and Ad5/F35-EGFP+Ad-p53 groups (P<0.05). (B) Cell apoptosis was determined at $48 \mathrm{~h}$ post-infection by TUNEL staining. (C) Data are expressed as percentage of apoptosis-positive cells examined with TUNEL. Bar graphs represent the mean values of triplicate determinations \pm SD. Lane 1, Ad5/F35-EGFP+Ad-EGFP; lane 2, Ad5/F35- siAPE1+Ad-EGFP; lane 3, Ad5/F35-EGFP+Ad-p53; lane 4, Ad5/F35-siAPE1+Ad-p53. "P<0.05, ${ }^{* *}$ P<0.01 vs. Ad5/F35-EGFP+Ad-EGFP; ${ }^{*} \mathrm{P}<0.01$ vs. Ad5/F35-siAPE1+Ad-EGFP; ${ }^{\$} \mathrm{P}<0.01$ vs. Ad5/F35-EGFP +Ad-p53.

Ad5/F35-siAPE1 and/or Ad-p53 treatment, immunohistochemistry was performed in human SMMC-7721 xenografts. In the Ad5/F35-EGFP+Ad-EGFP control group, APE1 protein was predominantly localized in the nucleus of tumor cells, and the expression level of APE1 was revealed to be the same in the Ad5/ F35-EGFP+Ad-EGFP and Ad5/F35-EGFP+Ad-p53 group, while the expression level of APE1 significantly decreased in the Ad5/ F35-siAPE1+Ad-EGFP and Ad5/F35-siAPE1+Ad-p53 groups (Fig. 5). Moreover, no p53 protein expression was observed in the Ad5/F35-EGFP+Ad-EGFP and Ad5/F35-siAPE1+Ad-EGFP groups, whereas the p53 protein level significantly increased in the Ad5/F35-EGFP+Ad-p53 and Ad5/F35-siAPE1+Ad-p53 groups (Fig. 5).

Combined treatment with Ad5/F35-siAPE1 and Ad-p53 inhibits tumor growth. We showed that the expression of APE1 protein in SMMC-7721 xenografts was inhibited by Ad5/F35-siAPE1, and the $\mathrm{p} 53$ protein expression was potentiated by Ad-p53. To investigate whether the combination of Ad5/F35-siAPE1 and Ad-p53 could enhance the inhibition of tumor growth in vivo, tumor-bearing mice were injected intratumorally with or without Ad5/F35-siAPE1 and/or Ad-p53 every three days. We initiated in vivo tumor therapy on Day 0 , which corresponded to 12 days following SMMC-7721 cell injection. As shown in
Fig. 6, we noted an inhibition of tumor growth in groups of mice treated with Ad5/F35-siAPE1+Ad-p53, Ad5/F35-siAPE1+AdEGFP and Ad5/F35-EGFP+Ad-p53 vs. the control group. Furthermore, Ad5/F35-siAPE1 in combination with Ad-p53 caused a significant inhibition of tumor growth compared with the Ad5/F35-siAPE1+Ad-EGFP or the Ad5/F35-EGFP+Ad-p53 group. On Day 18, the tumor-inhibition rates of the Ad5/F35-siAPE1+Ad-EGFP group, the Ad5/F35-EGFP+Ad-p53 group and the Ad5/F35-siAPE1+Ad-p53 group were 29.0, 46.47 and $86.87 \%$, respectively $(\mathrm{P}<0.05)$.

Combination of Ad5/F35-siAPE1 and Ad-p53 enhances apoptosis induction in vivo. To investigate the effects of combined Ad5/F35-siAPE1 and Ad-p53 on apoptosis induction in vivo, the apoptosis index was calculated using an in situ apoptosis detection assay. As shown in Fig. 7A and B, apoptosis index in Ad5/F35-siAPE1+Ad-p53, Ad5/F35-EGFP+Ad-p53, Ad5/F35-siAPE1+Ad-EGFP and Ad5/F35-EGFP+Ad-EGFP was $22.12 \pm 3.99,8.23 \pm 1.60,6.85 \pm 1.11$ and $3.06 \pm 1.35 \%$, respectively. The Ad5/F35-siAPE1+Ad-EGFP and Ad5/F35EGFP+Ad-p53 groups induced a slightly higher apoptosis index than the Ad5/F35-EGFP+Ad-EGFP control group, whereas Ad5/F35-siAPE1 in combination with Ad-p53 caused a significantly higher apoptosis index. 


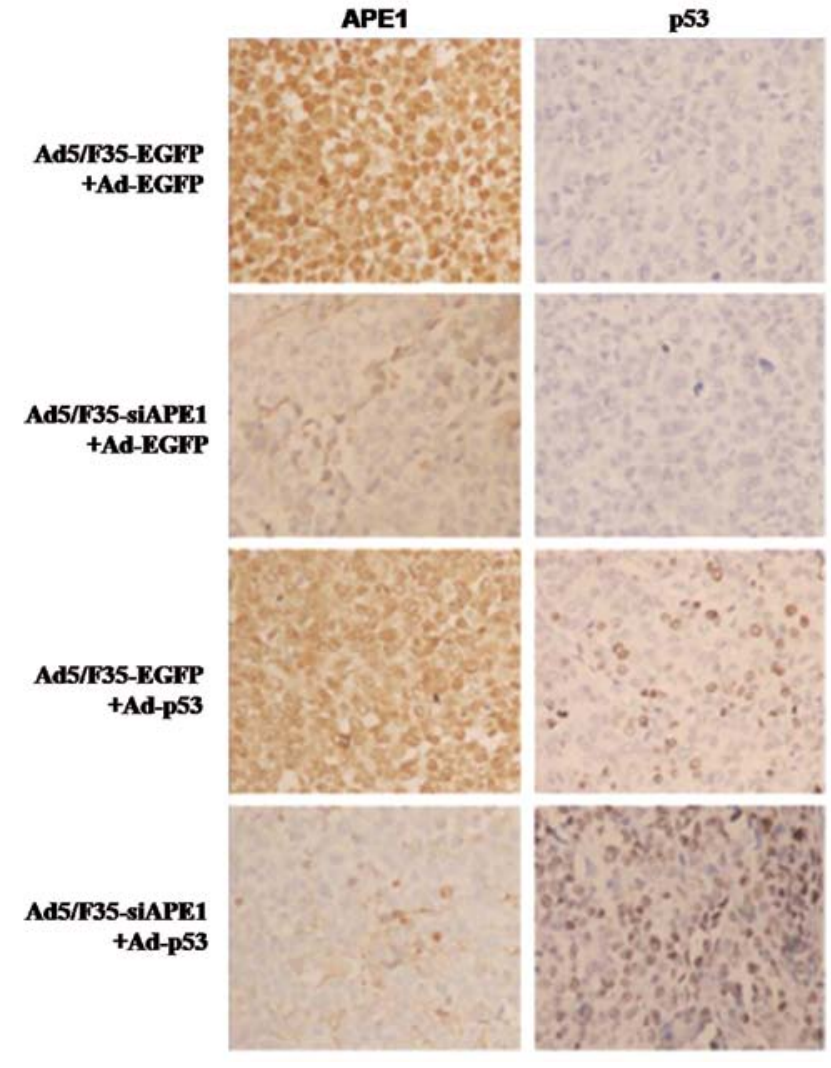

Figure 5. Analysis of APE1 and p53 protein expression by immunohistochemistry in SMMC-7721 xenografts. Tumor tissue samples from Ad5/ F35-EGFP+Ad-EGFP, Ad5/F35-siAPE1+Ad-EGFP, Ad5/F35-EGFP+Ad-p53 and Ad5/F35-siAPE1+Ad-p53 groups were subjected to APE1 and p53 antibodies by using immunohistochemistry.

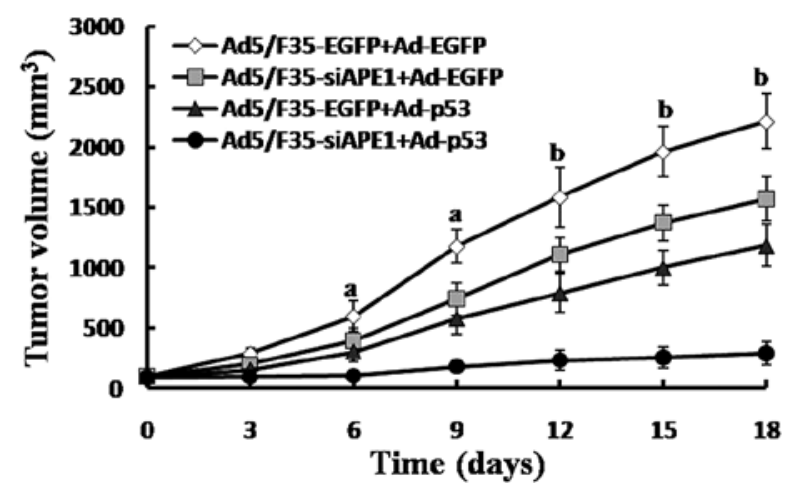

Figure 6. Combined Ad5/F35-siAPE1 and Ad-p53 inhibit tumor growth. Tumor-bearing mice were injected with Ad5/F35-siAPE1 and/or Ad-p53 directly into the tumors every three days. Tumor growth was measured in two dimensions and tumor volume was recorded. Day 0 is the first day of infection and tumor volumes represented on graphs begin on Day 0. (a) The tumor volume of the Ad5/F35-siAPE1+ Ad-p53 group differed significantly from the Ad5/F35-EGFP+Ad-EGFP control group, but there were no statistical differences between the Ad5/F35-siAPE1+Ad-EGFP and Ad5/ F35-EGFP+Ad-p53 groups. (b) The tumor volume differed significantly among all treated groups $(\mathrm{P}<0.05)$.

\section{Discussion}

The p53 gene, regarded as the genome guardian of cells, plays an important role in cell cycle control, apoptosis and tumor growth inhibition. It is absent or mutated in approximately half
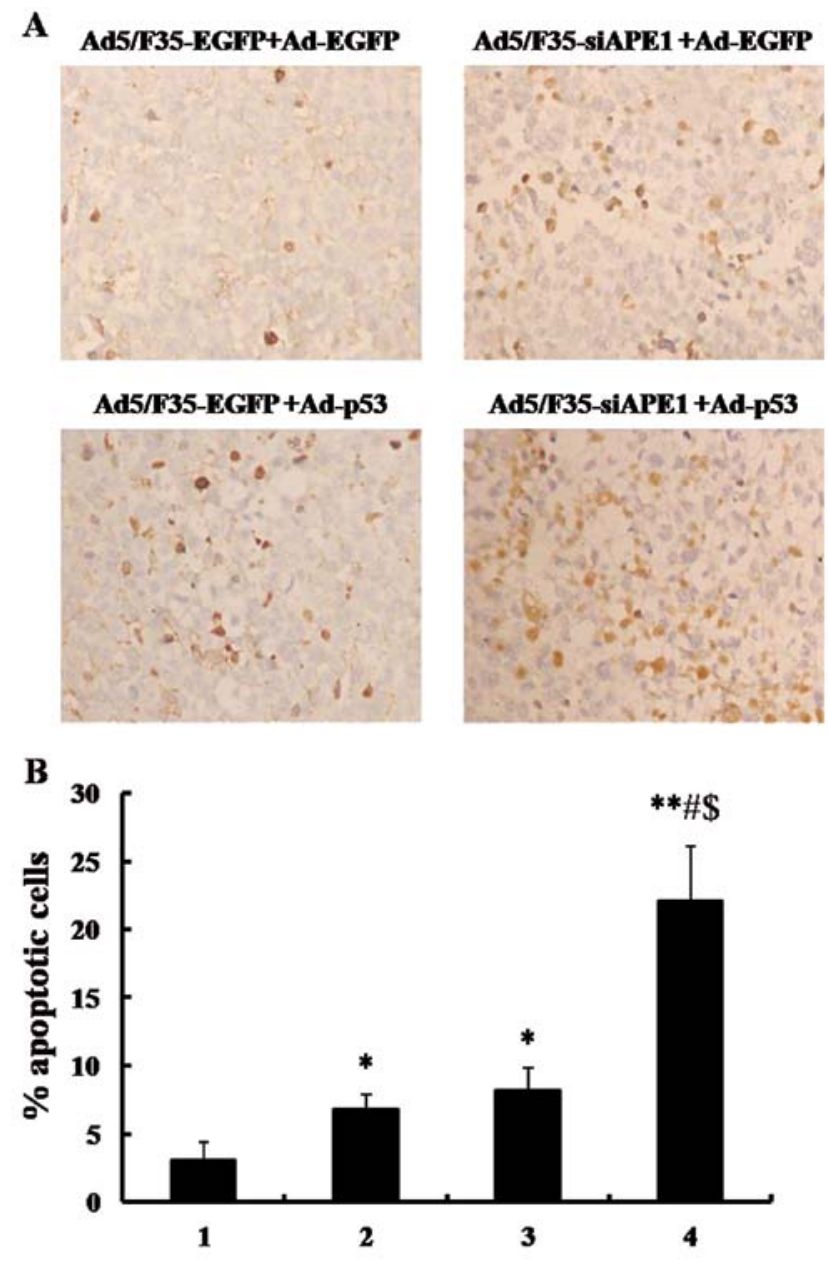

Figure 7. Combined treatment with Ad5/F35-siAPE1 and Ad-p53 potentiates apoptosis induction in vivo. (A) Paraffin-embedded sections were made and apoptosis was determined by TUNEL staining. (B) Data are expressed as percentage of apoptosis-positive cells examined with TUNEL. Bar graphs represent the mean values of triplicate determinations $\pm \mathrm{SD}$ Lane 1, Ad5/F35-EGFP+Ad-EGFP; lane 2, Ad5/F35-siAPE1+Ad-EGFP; lane 3, Ad5/F35-EGFP+Ad-p53; lane 4, Ad5/F35-siAPE1+Ad-p53. 'P<0.05, ${ }^{* * *} \mathrm{P}<0.01$ vs. Ad5/F35-EGFP+Ad-EGFP; ${ }^{~} \mathrm{P}<0.01$ vs. Ad5/F35-siAPE1+AdEGFP; ${ }^{\text {P }}<0.01$ vs. Ad5/F35-EGFP+Ad-p53.

of all types of human cancer $(25,26)$. The incidence of the p53 mutation was $61 \%$ in $\mathrm{HCC}$ and its presence indicates a poorer prognosis $(4,5)$. Wild-type p53 promotes cell cycle arrest and apoptosis of tumor cells following radiation or chemotherapy, but p53 loss abrogates the effective apoptotic response and induces radio- and chemoresistance $(2,3)$. As a potentially effective approach, clinical trials of Ad-p53 as a single agent or combined with radio- or chemotherapy are ongoing in patients with head and neck squamous cell carcinoma, non-small cell lung cancer, glioma, breast cancer, bladder and esophageal cancer $(7-10,27)$. However, gene transfer of p53 alone does not always have a positive therapeutic outcome in all human types of cancer $(7,28,29)$, thus, combined gene therapy is urgently required. In the present study, Ad-p53 alone inhibited cell proliferation of the SMMC-7721 cell line, increased p53 expression levels and induced partial tumor regression in an HCC murine model. These data are in line with previous reports $(11,12)$, suggesting the potential role of Ad-p53 in the treatment of HCC. 
APE1, with dual functions of DNA repair and redox regulation activity of transcription factors, is generally abundantly expressed in most cells and is mainly localized in nuclei of normal cells (13). APE1 is the major apurinic/apyrimidinic (AP) endonuclease in the DNA base excision repair (BER) pathway, which plays a critical role in repairing DNA damage (30). In addition to its DNA repair function, APE1 is also a multifunctional protein that is involved in other crucial cellular processes, including the response to oxidative stress, regulation of transcription factors, cell cycle control and apoptosis (31). As a redox factor, APE1 controls the redox status of a number of transcription factors, including hypoxia inducible factor- $\alpha$ (HIF- $\alpha)$, nuclear factor- $\kappa \mathrm{B}(\mathrm{NF}-\kappa \mathrm{B}), \mathrm{p} 53$, cAMP response element binding protein (CREB), thyroid transcription factor 1 (TTF-1), paired box 5 (Pax5) and 8 (Pax8) (31).

The functional importance of APE1 is underscored by the embryonic lethality of APE1 murine knockouts at very early stages (E3.5-E9.5) and the lack of viable cell lines completely deficient for the APE1 gene $(32,33)$. Several studies demonstrated that APE1 was highly expressed in several human tumors, and increased APE1 expression has been shown to be associated with resistance to radiotherapy and chemotherapy (16-21). Previous studies using DNA antisense methodology implicated APE1 in cellular resistance to a variety of agents that cause alkylation and oxidative DNA damage. Targeted reduction of APE1 by specific antisense oligonucleotides in human HeLa, rat glioma, or human lung carcinoma cells renders mammalian cells hypersensitive to alkylating and oxidative agents, as well as ionizing radiation (31,34-36). Therefore, APE1 has been approved to be a viable target for cancer therapeutics. In the present study, we used Ad5/F35-si APE1 in a murine model of HCC using the SMMC-7721 cell line. Data presented here show that intratumoral injection of Ad5/F35-siAPE1 was able to suppress APE1 expression and tumor growth and increase apoptosis. These data are in accordance with a report by Xiang et al (22), indicating the effective role of Ad5/F35-si APE1 in the treatment of cancer.

As the therapeutic efficacy of monogene therapy is disappointing, combined multi-targeting gene therapy is urgently required to alleviate the suffering caused by cancer and to minimize the mortality rate. The multi-targeting gene therapy by combination of epidermal growth factor receptor ligand epiregulin (EREG), cyclooxygenase 2 (COX2), and matrix metalloproteinases 1 and 2 (MMP1 and MMP2) produced a significant inhibition of pulmonary metastasis of human breast cancer compared with either therapy alone (37). Compared with the suicide gene thymidine kinase and interleukin 2 (IL-12) gene therapy alone, the combination resulted in inhibited tumor growth and prolonged animal survival in a murine HCC model $(11,12)$. Combined B7.1 and angiostatin completely eradicated large $(0.4 \mathrm{~cm}$ in diameter) EL-4 lymphomas which were established in syngeneic C57BL/6 mice, whereas B7.1 and angiostatin monotherapies were ineffective (38). These studies indicate that combined gene therapy may be an effective approach against cancer. In our study, we combined Ad5/ F35-siAPE1 and Ad-p53. Our data demonstrate that combination therapy is more effective in vitro and in treating an $\mathrm{HCC}$ murine model than therapy with a single vector, which is in accordance with the previous studies in $\operatorname{HCC}(11,12)$. In the HCC murine model here, we found that the tumor-inhibition rate and apoptosis index in the combined Ad5/F35-siAPE1 plus Ad-p53 group significantly increased. However, treatment with either Ad5/F35-siAPE1 or Ad-p53 induced a slight increase in tumor-inhibition rate and apoptosis index.

In conclusion, our data demonstrate that combination therapy of Ad5/F35-siAPE1 and Ad-p53 was more efficient than therapy with either vector alone in vitro and in a murine HCC model. Ad-p53, as a gene therapy agent, can be combined with Ad5/F35-siAPE1 due to its chemo- and radiosensitized efficacy in cancer, and represents a potential therapeutic approach for patients with cancer. Furthermore, the clinical use of Ad5/F35-siAPE1 in combination with Ad-p53 has yet to be explored and warrants further investigations in human HCC patients.

\section{Acknowledgements}

The study was financially supported by the National Natural Science Foundation of China (no. 30872975 to D.W.).

\section{References}

1. Bosch FX, Ribes J, Cleries R and Diaz M: Epidemiology of hepatocellular carcinoma. Clin Liver Dis 9: 191-211, 2005.

2. Lowe SW, Ruley HE, Jacks T and Housman DE: p53-dependent apoptosis modulates the cytotoxicity of anticancer agents. Cell 74: 957-967, 1993.

3. Eisold S, Linnebacher M, Ryschich E, et al: The effect of adenovirus expressing wild-type p53 on 5-fluorouracil chemosensitivity is related to 553 status in pancreatic cancer cell lines. World J Gastroenterol 10: 3583-3589, 2004.

4. Honda K, Sbisa E, Tullo A, et al: p53 mutation is a poor prognostic indicator for survival in patients with hepatocellular carcinoma undergoing surgical tumour ablation. Br J Cancer 77: 776-782, 1998.

5. Hsia CC, Nakashima Y, Thorgeirsson SS, et al: Correlation of immunohistochemical staining and mutations of p53 in human hepatocellular carcinoma. Oncol Rep 7: 353-356, 2000.

6. Clayman GL, Frank DK, Bruso PA and Goepfert H: Adenovirusmediated wild-type p53 gene transfer as a surgical adjuvant in advanced head and neck cancers. Clin Cancer Res 5: 1715-1722, 1999.

7. Nemunaitis J, Swisher SG, Timmons T, et al: Adenovirusmediated p53 gene transfer in sequence with cisplatin to tumors of patients with non-small-cell lung cancer. J Clin Oncol 18: 609-622, 2000.

8. Swisher SG, Roth JA, Komaki R, et al: Induction of p53-regulated genes and tumor regression in lung cancer patients after intratumoral delivery of adenoviral p53 (INGN 201) and radiation therapy. Clin Cancer Res 9: 93-101, 2003.

9. Lang FF, Bruner JM, Fuller GN, et al: Phase I trial of adenovirusmediated p53 gene therapy for recurrent glioma: biological and clinical results. J Clin Oncol 21: 2508-2518, 2003.

10. INGN 201: Ad-p53, Ad5CMV-p53, adenoviral p53, p53 gene therapy - introgen, RPR/INGN 201. Drugs R D 8: 176-187, 2007.

11. Drozdzik M, Qian C, Xie X, et al: Combined gene therapy with suicide gene and interleukin-12 is more efficient than therapy with one gene alone in a murine model of hepatocellular carcinoma. J Hepatol 32: 279-286, 2000.

12. Su H, Lu R, Ding R and Kan YW: Adeno-associated viral-mediated gene transfer to hepatoma: thymidine kinase/interleukin 2 is more effective in tumor killing in non-ganciclovir (GCV)-treated than in GCV-treated animals. Mol Ther 1: 509-515, 2000.

13. Duguid JR, Eble JN, Wilson TM and Kelley MR: Differential cellular and subcellular expression of the human multifunctional apurinic/apyrimidinic endonuclease (APE/ref-1) DNA repair enzyme. Cancer Res 55: 6097-6102, 1995.

14. Hanson S, Kim E and Deppert W: Redox factor 1 (Ref-1) enhances specific DNA binding of $\mathrm{p} 53$ by promoting $\mathrm{p} 53$ tetramerization. Oncogene 24: 1641-1647, 2005.

15. Jayaraman L, Murthy KG, Zhu C, Curran T, Xanthoudakis S and Prives C: Identification of redox/repair protein Ref-1 as a potent activator of p53. Genes Dev 11: 558-570, 1997. 
16. Herring CJ, West CM, Wilks DP, et al: Levels of the DNA repair enzyme human apurinic/apyrimidinic endonuclease (APE1, APEX, Ref-1) are associated with the intrinsic radiosensitivity of cervical cancers. Br J Cancer 78: 1128-1133, 1998.

17. Moore DH, Michael H, Tritt R, Parsons SH and Kelley MR: Alterations in the expression of the DNA repair/redox enzyme APE/ref-1 in epithelial ovarian cancers. Clin Cancer Res 6: 602-609, 2000.

18. Robertson KA, Bullock HA, Xu Y, et al: Altered expression of Ape1/ref-1 in germ cell tumors and overexpression in NT2 cells confers resistance to bleomycin and radiation. Cancer Res 61: 2220-2225, 2001.

19. Bobola MS, Blank A, Berger MS, Stevens BA and Silber JR: Apurinic/apyrimidinic endonuclease activity is elevated in human adult gliomas. Clin Cancer Res 7: 3510-3518, 2001.

20. Koukourakis MI, Giatromanolaki A, Kakolyris S, et al: Nuclear expression of human apurinic/apyrimidinic endonuclease (HAP1/Ref-1) in head-and-neck cancer is associated with resistance to chemoradiotherapy and poor outcome. Int J Radiat Oncol Biol Phys 50: 27-36, 2001 .

21. Wang D, Luo M and Kelley MR: Human apurinic endonuclease 1 (APE1) expression and prognostic significance in osteosarcoma: enhanced sensitivity of osteosarcoma to DNA damaging agents using silencing RNA APE1 expression inhibition. Mol Cancer Ther 3: 679-686, 2004.

22. Xiang DB, Chen ZT, Wang D, et al: Chimeric adenoviral vector Ad5/F35-mediated APE1 siRNA enhances sensitivity of human colorectal cancer cells to radiotherapy in vitro and in vivo. Cancer Gene Ther 15: 625-635, 2008.

23. Zhang Y, Wang J, Xiang D, Wang D and Xin X: Alterations in the expression of the apurinic/apyrimidinic endonuclease-1/redox factor-1 (APE1/Ref-1) in human ovarian cancer and indentification of the therapeutic potential of APE1/Ref-1 inhibitor. Int J Oncol 35: 1069-1079, 2009

24. Wang D, Xiang DB, Yang XQ, et al: APE1 overexpression is associated with cisplatin resistance in non-small cell lung cancer and targeted inhibition of APE1 enhances the activity of cisplatin in A549 cells. Lung Cancer 66: 298-304, 2009.

25. Levine AJ, Momand J and Finlay CA: The p53 tumour suppressor gene. Nature 351: 453-456, 1991.
26. Hollstein M, Sidransky D, Vogelstein B and Harris CC: p53 mutations in human cancers. Science 253: 49-53, 1991.

27. Clayman GL, el-Naggar AK, Lippman SM, et al: Adenovirusmediated p53 gene transfer in patients with advanced recurrent head and neck squamous cell carcinoma. J Clin Oncol 16: 2221-2232, 1998.

28. Roth JA, Nguyen D, Lawrence DD, et al: Retrovirus-mediated wild-type p53 gene transfer to tumors of patients with lung cancer. Nat Med 2: 985-991, 1996.

29. Swisher SG, Roth JA, Nemunaitis J, et al: Adenovirus-mediated p53 gene transfer in advanced non-small-cell lung cancer. J Natl Cancer Inst 91: 763-771, 1999.

30. Fleck O and Nielsen O: DNA repair. J Cell Sci 117: 515-517, 2004

31. Evans AR, Limp-Foster M and Kelley MR: Going APE over ref-1. Mutat Res 461: 83-108, 2000.

32. Xanthoudakis S, Smeyne RJ, Wallace JD and Curran T: The redox/DNA repair protein, Ref-1, is essential for early embryonic development in mice. Proc Natl Acad Sci USA 93: 8919-8923, 1996.

33. Larsen E, Meza TJ, Kleppa L and Klungland A: Organ and cell specificity of base excision repair mutants in mice. Mutat Res 614: 56-68, 2007.

34. Walker LJ, Craig RB, Harris AL and Hickson ID: A role for the human DNA repair enzyme HAP1 in cellular protection against DNA damaging agents and hypoxic stress. Nucleic Acids Res 22: 4884-4889, 1994

35. Ono Y, Furuta T, Ohmoto T, Akiyama K and Seki S: Stable expression in rat glioma cells of sense and antisense nucleic acids to a human multifunctional DNA repair enzyme, APEX nuclease. Mutat Res 315: 55-63, 1994.

36. Chen DS and Olkowski ZL: Biological responses of human apurinic endonuclease to radiation-induced DNA damage. Ann NY Acad Sci 726: 306-308, 1994.

37. Gupta GP, Nguyen DX, Chiang AC, et al: Mediators of vascular remodelling co-opted for sequential steps in lung metastasis. Nature 446: 765-770, 2007.

38. Sun X, Kanwar JR, Leung E, Lehnert K, Wang D and Krissansen GW: Angiostatin enhances B7.1-mediated cancer immunotherapy independently of effects on vascular endothelial growth factor expression. Cancer Gene Ther 8: 719-727, 2001. 